This is the final peer-reviewed accepted manuscript of:

Silvia Mirri, Catia Prandi, Marco Roccetti \& Paola Salomoni (2017) Walking under a Different Sky: Urban Colored Routes for Creative Engagement and Pleasure, International Journal of Human-Computer Interaction, 33:12, 1010-1021.

The final published version is available online at: http://dx.doi.org/10.1080/10447318.2017.1321218

Rights / License:

The terms and conditions for the reuse of this version of the manuscript are specified in the publishing policy. For all terms of use and more information see the publisher's website.

This item was downloaded from IRIS Università di Bologna (https://cris.unibo.it/)

When citing, please refer to the published version. 


\title{
Walking under a different sky: urban colored routes for creative engagement and pleasure
}

\author{
Silvia Mirri*, Catia Prandi, Marco Roccetti, Paola Salomoni \\ Department of Computer Science and Engineering, \\ University of Bologna, \\ Mura Anteo Zamboni 7, 40126, Bologna, Italy \\ *Corresponding author: E-mail: silvia.mirri@unibo.it \\ Tel: +39-0547-338813 \\ Fax: +39-0547-338890
}

\begin{abstract}
This work presents a study inviting new reflections on our daily walking experiences as mediated by modern GIS-based route-mapping software tools, which has culminated into ColorPath: an app that allows walkers to follow creative urban paths computed on the basis of their walking preferences and expressed under the form of a color. In particular, users may indicate their preference to follow a route as obtained as an urban mix of: pleasurable landscapes (blue), historical buildings and places (red) and parks and gardens (green). ColorPath computes a corresponding path to be followed. Drawing on a new trend that explores
\end{abstract}


the relations between GIS-enabled computerized navigations and socio-cultural practices, ColorPath has been built on top of OpenTripPlanner and exploits OpenStreetMap data. Studies of ten people's use of ColorPath propose insights on how walkers reflect on the differences (pros and drawbacks) between "colored" routes and traditional shortest paths computed by routinary route recommendation algorithms.

Keywords: multimedia mobile app, route recommendation algorithms, urban environments, social-cultural practices.

\section{Introduction}

Color is one of the most immediate methods for conveying media messages [Eiseman 2000], [Eiseman 2006]. Color can symbolize thoughts and it can significantly contribute to aesthetic, emotional, and stylistic impressions of what is being visualized [Csurka et al. 2010], [Ling and Schaik, 2002]. It can communicate a mood or elicit a particular emotion and it can influence attitudes, perceptions, and behaviors [Cyr et al. 2010], [Bonnardel et al. 2011]. Color plays a substantial role in how we feel, act and respond to our surroundings [Valdez and Mehrabian, 1994].

It was March 2011, when the first Color Run took place in Phoenix, Arizona, with 6,000 participants, with the aim of promoting healthiness and happiness, involving both professionals and novices in a five kilometers run (https://thecolorrun.com/). Neither winners nor prizes in this competition, but runners are showered with colored powder at specific stations along the run, getting inspired by the Hindu festival of Holi [Ebeling, 2009]. Since that first event, the Color Run has reached a great success, and it has held hundreds of events worldwide, 
increasing the number of participants every year. The trend of this event success is increasing and it represents an interesting experience of the use of colors within events placed in urban environments.

Color characterizes our cities, by adding visual richness as an expression of its urban elements combined with its culture [Boeschenstein, 1986]. Different areas and streets of a city are tinted with different colors, with a prominent one, which features and represents that specific district or neighborhood [Guo and Cai, 2012]. Hence, citizens and walkers who are wandering in that area of the city are naturally surrounded by that prominent color. Our idea is to exploit those colors of the city so as to let the citizens personalize their urban paths according to their mood of the moment or according to the feeling they would like to experience.

In order to reach this goal, we have exploited the wide diffusion of mobile devices equipped with geolocation sensors: they have undoubtedly contributed to the emergence and the success of applications that exploit geographical maps and spatial representations of data. Such applications are usually based on Geographical Information Systems and on routing algorithms used to compute the shortest paths in terms of distance between the starting point and the destination or in terms of travel time. Unfortunately, this does not always fit with the mood and with the preferences of the walkers, who could prefer different routes, including characteristic historical areas of the city or scenic view or gardens, so as to improve the experience of their paths.

Suggesting walking routes different from the shortest ones is the goal of some related studies. For instance Quercia et al. have investigated the computation of emotionally pleasant paths [Quercia et al. 2014], while Rosner and co-authors have studied the effect on walkers of routes generated on the basis of digital sketches people have created and annotated without a map [Rosner et al. 2015]. 
In this paper, we present ColorPath, a web-based mobile application that computes a pedestrian path between two points in a given city, including a mixture of urban elements chosen on the basis of a specific color requested by the user and keeping the distance around the shortest one, as detailed in the following. We got inspired by the RGB additive color model and we set the ColorPath interaction mechanism letting the user choose the color of the route by means of a Color Triangle [Backhaus et al., 1998], as a combination of the three primary colors: Red, Green and Blue. Each type of urban element is mapped into a color as discussed in Section 3.

The ColorPath routing algorithm is based on OpenTripPlanner and it exploits OpenStreetMap data, which are associated to Points on Interest, nodes, ways, and relations in the urban environment.

We involved 10 people in field trials, with the aim of providing qualitative evaluations of ColorPath, so as to assess if and how much the proposed colored path varies the color the user has set. Results show that our approach is feasible, meeting users' appreciation in the most of the cases. In particular, our main findings can be listed as:

- Our ColorPath algorithm proposes a path identified by a color, which represents the mixture of three categories of urban elements (historical and cultural, green and open urban space ones). During our field trials, the users perceived the colors of the proposed path as similar to the chosen ones. In particular, the Euclidean distance between the chosen color and the perceived one is very short as discussed in the rest of this paper.

- ColorPath proposes longer paths, compared with the ones proposed by other GIS-based applications (e.g. Google Maps) with the same starting point and destination. According to our users' evaluation, this is not perceived as a negative issue. This confirms the results obtained in previous [Mirri et al. 2016] and related studies [Quercia et al. 2014]. 
- All the users enjoy the proposed paths. Nine users declared they would use ColorPath so as to explore different paths across the city, discovering new slices of the city. Only one user claimed that he would avoid new routes, preferring the already well-known ones.

The remainder of the paper is organized as follows. Section 2 describes background and related work, while Section 3 presents the ColorPath application, detailing its preferences system and interaction and its routing algorithm. Section 4 reports the tests with users we have performed and discusses the obtained results. Finally, Section 5 concludes the paper illustrating main findings and further work.

\section{Colors and Maps}

Color is undoubtedly an inseparable part of our everyday lives and its presence is evident in everything that we perceive with our sight [Kaya and Epps, 2004]. A wealth of research is devoted to investigate colors from different points of view, ranging from physics of color [Waldman 2002], to color perception in humans' eyes and brain [von Helmholtz, 1925]. In particular, colorimetry (i.e. color science) defines color stimuli as being characterized by hue (i.e. wavelength), brightness or value (i.e. black-to-white quality), and saturations or chroma (i.e., purity or vividness with lower saturation colors containing more grey).

Perception of colors is not limited to physical and anatomical aspects. In fact, colors have been studied also from philosophical, anthropological, and psychological perspective for many years [Levy, 1984]. In particular, psychology of color spans more than a century and covers a wide range of interests, including color preferences, color effects on emotions, color effects on behavior and reactions to color concepts [Valdez and Mehrabian, 1994]. Studies show that colors may have different effects on the emotion and such differences may be due to cultural differences, psychological situations, and age factors, since they may affect the perception of 
colors [Terwogt and Hoeksma, 1995]. Results of such studies are taken into account in several contexts, and that is why some specific colors are used to paint some specific objects or some specific indoor environments. For instance, restaurants prefer yellow and red colors to whet the customer's appetite, while hospitals have green rooms to soothe patients during their recovery [Murray and Deabler, 1957]. Moreover, colors characterize the urban environment of our cities [Boeschenstein, 1986]. Color adds visual richness to our cities and this characteristic is exploited in city design. The color of the city concerns the environment and the culture, which is the concrete form of city life involving all the citizens [Guo and Cai, 2012]. We can define the "color of the city" as a comprehensive account of the elements, meanings and characteristics of colors in the city. Hence, it is a general appearance of city color of natural as well as artificial landscape such as buildings, and color of clothing and street decoration. The general scene of color in the city is composed by geographical color and culture ones [Boeschenstein, 1986]. The common genes and distinct characteristic of city color make it an element best representing local culture and history in the construction of city identity [Guo and Cai, 2012]. Mary McCarthy in [McCarthy, 1959] (pp. 375) has viewed Florence and neighboring Italian cities in terms of their respective colors: “... the ochre-and-dun file of hotels and palazzi has the spruce, spare look of a regiment drawn up in drill order. The deep shades of melon and tangerine that you see in Rome, the pinks of Venice, the rose of Siena, the red of Bologna have been ruled out of Florence as if by municipal degree."

In particular, the red color strongly characterizes the city of Bologna (see Figure 1) and it is the reason of ones of its nicknames: "the red one" ("la rossa", in Italian), referring to the reflection of the building roofs and of the bricks with which towers and palazzos were built in the old town [Noyes, 2009]. 


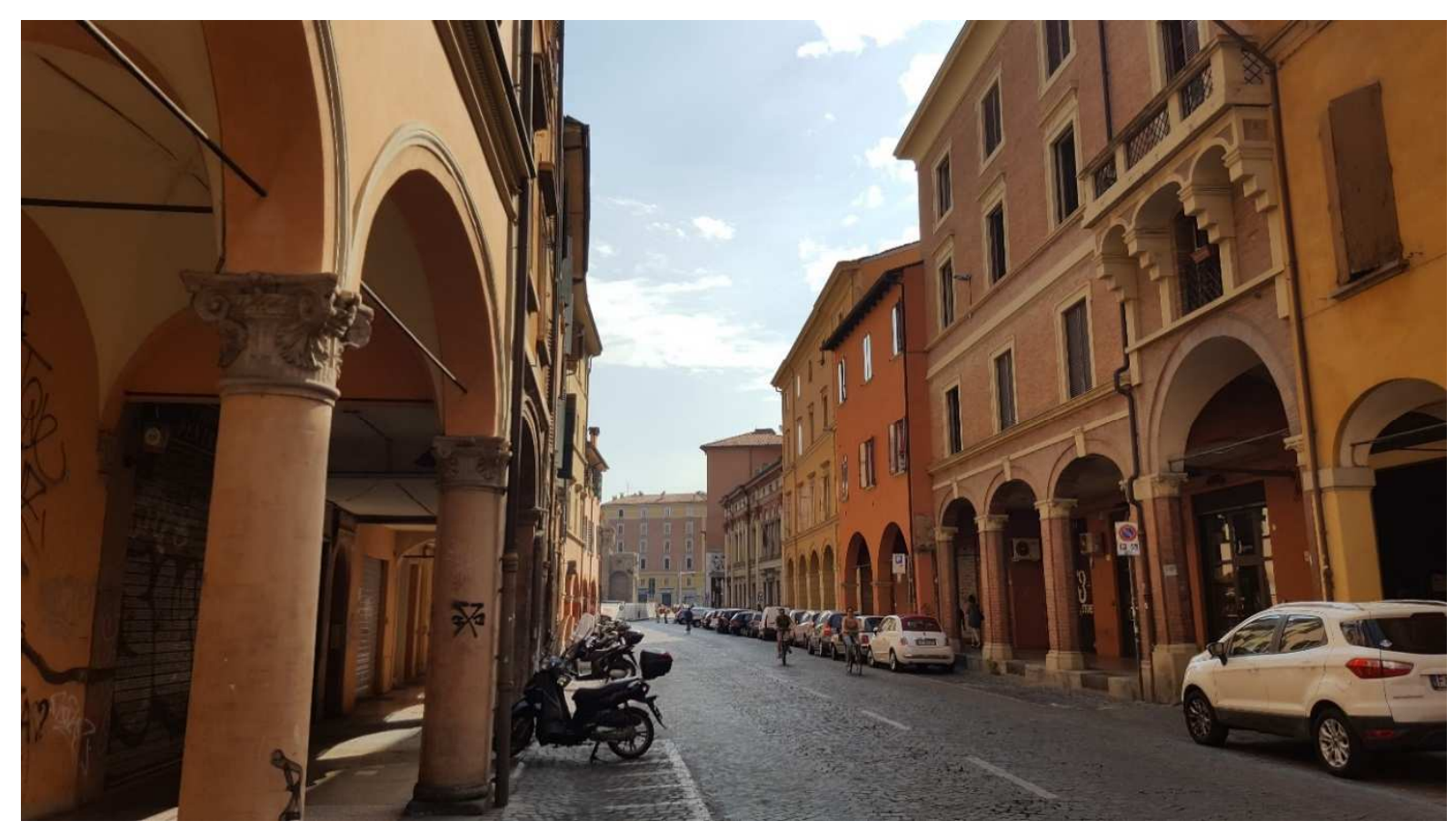

Figure 1. A street in Bologna old town.

In this context, GIS-based applications, designed to be used by means of mobile devices (equipped with GPS sensors) could be exploited with the aim of letting citizens explore the city in a new way, letting them choose different urban paths, going outside their traditional or most commonly used trails and meeting their personal mood of the moment.

Maps are symbolic representations of relationships between elements of some space, highlighting regions and themes. Many maps are two-dimensional representations of threedimensional space, most commonly used to depict geography. Geographic maps of territory have a very long tradition, existing from ancient times, and they historically refer to a twodimensional representation of the surface of the world [Rosner et al., 2015]. According to Denis Wood (cartographer and author of "The Power of Maps" and "Rethinking the Power of Maps" [Wood and Fels, 1992], [Wood et al, 2010]), maps are becoming a means for categorizing interests. In fact, in Wood's vision any map advances a specific interest, serving a precise purpose [Wood et al. 2006]. The evolution of digital artifacts and of networking technologies 
has caused the transition from traditional maps to multimodal, interactive maps for GIS (Geographic Information Systems) [Oviatt, 1997], [Brock. 2015]. Google Maps and GPSbased navigators are selective and provide an algorithmic solution to serve a standardized purpose: equip the user with the fastest and the shortest trail, without taking into account any other issue, preference or need that s/he could have. A path computed by a GIS is characterized by being destination-oriented, precise, and planned.

The idea of providing different ways of computing paths within an urban environment has been recently explored in recent studies. In particular, Daniela Rosner et al. proposed to transform hand-drawn digital sketches into walking paths [Rosner et al., 2015]; while Daniele Quercia et al. investigated the idea of suggesting routes that are emotionally pleasant instead of being short and fast [Quercia et al., 2014].

Moreover, paths provided by route recommendation algorithms are computed to serve a representative user, excluding the possibility of meeting preferences and needs of people who do not correspond to that hypothetic user [Muller et al., 2001], [Gaunet and Briffault, 2015]. In particular, route calculation algorithm usually take into consideration just few users' categories, which are merely characterized by the means of transport they use. For this reason, some specific routing systems have been developed with the aim of meeting specific users' needs (e.g. for runners, frequent walkers, wheelchair people [Roccetti et al. 2011], citizens engaged in multimodal paths [Mirri et al., 2014a]) and some studies have been conducted in this sense [Mirri et al., 2014b], [Prandi et al., 2015], [Palazzi et al., 2010].

In our ColorPath project, we aimed to investigate a mechanism to equip citizens with urban walks computed on the basis of color combinations they choose, hence reflecting or influencing their personal mood. The proposed walks correspond to a specific mixture of urban elements, which accompany the walkers in their paths in the city. 


\section{The ColorPath Application}

The ColorPath application has been designed and implemented on the basis of OpenTripPlanner (OTP), an open source platform for multimodal journey planning (http://www.opentripplanner.org/). Paths are computed by exploiting OpenStreetMap (OSM) data. OSM is a free, editable map of the world that is built by volunteers and released with an open content license (http://openstreetmap.org/). Moreover, OSM data include information about physical features (nodes, ways, and relations), and different geographic attributes (called tags) too, which can describe specific features, composed by a key and a value (http://wiki.openstreetmap.org/wiki/Map_Features).

With ColorPath, we extended the OTP routing engine to compute pedestrian paths keeping into account preferences related to:

(i) Cultural and historical issues: they include monuments (e.g. historical buildings and palazzos, churches, museums, fountains, towers), typical streets and architectural elements (such as porticos and arcades in Bologna [Noyes, 2009]).

(ii) Green issues: they include parks, gardens, tree-lined streets, and, in general, green areas and any corner related to the nature that could be placed in the city.

(iii) Urban open space issues: any urban space (e.g. squares) where the citizens can enjoy the blue of the sky or panoramas and scenic views.

Each node, way, and relation in the urban map is characterized by the presence of one or more of these issues. By associating a primary color to those three previous issues, it is possible to assign a color to an urban path. Such a color is resulting from the combination of the primary ones and it represents a specific mixture of the urban elements which composed the related path and which accompany the citizen during that walk in the city.

The assignment of the green color goes obviously to parks and gardens, while the blue one was attached to panoramas and scenic views. Finally, the assignment of the red color to cultural 
and historical monuments was motivated by the fact that we conducted our experiments in the city of Bologna. In Bologna, in fact, the main color of roofs and bricks of the historical buildings is red (as already mentioned), and this is the reason behind the nickname of the city: "the red one". It should be noticed that we decided to use only the primary colors for the sake of simplicity. Nothing prevents one to imagine an extension of our system that exploit nonprimary colors.

ColorPath has been designed and implemented as a web-based application, with the specific aim of being exploited while walking in the city with a mobile device equipped with GPS sensors.

In the following subsections, we are going to describe how we have managed the ColorPath Preferences System (to let the user choose the color of the path s/he would like to walk, according to his/her preferences and mood, in Subsection 3.1) and how we have defined the ColorPath Algorithm (with the aim of computing the best path on the basis of the information embodied in OSM and according to the chosen color, in Subsection 3.2).

\subsection{The ColorPath Preferences System}

The preferences are expressed in the form of colors, taking inspiration by the RGB color model, in which three primary color (Red, Green, and Blue) are added together to reproduce a broad array of colors. Each primary color is usually represented by an integer number, ranging from 0 to 255 , where 0 means that the color is absent, while 255 stands for the maximum saturation of that color. Hence, a tern of integer numbers (one for any primary color) represents each color.

Since our paper reports on a preliminary study where the experimental aspects prevail over any systematic approach, the association between OSM tags and colors (as shown in Table 1) comes as the result of an analysis of all the OSM tags which pertain the city of Bologna. The 
rationale behind this was our intention to go all the way, while finalizing the implementation of the system to demonstrate the efficacy of our ideas. Nonetheless, we recognize that this issue deserves further investigations since the problem of interest has a complex nature. For example, a different color interpretation can be assigned to each tag, depending on the person who takes the decision. Moreover, since OSM is an open source project, based on voluntary participation, the tags set can change over the time. In other words, automated color assignment to dynamic OSM tags could be confusing for users. All these reasons led us to the decision of avoiding the use of an algorithm to choose the tags and assign colors, while allowing each user to exploit the flexibility provided by the OSM project and the collaborative approach supported by OSM volunteered information.

Table 1 details how the three primary colors are linked with the OSM tags, which are relevant with the routing preferences system we implemented in the ColorPath application.

If the user chooses a primary color, it means that $s /$ he is interested in just one routing preference. In other words, that issue covers $100 \%$ of his/her preferences.

In order to let the user choose a color, we have equipped the ColorPath interface with a color triangle, inspired by the RGB one [Backhaus et al., 1998], where the primary colors are set at its corners. The user can choose a color within the area of the color triangle widget and then the chosen color is decomposed in the three primary colors and in the corresponding percentages of related urban issues. As an example, Figure 2 shows the ColorPath triangle, where the user is interested in just cultural/historical issues.

Interesting is the fact that the three primary colors can be combined to obtain a new color resulting in a path with different "amount" of each routing preference. In fact, the triangle widget allows users to specify any possible combination of colors, which matches to a related combination of urban elements placed in a corresponding path. For example, see Figure 3: the user selects the purple color in the triangle, coded in the RGB color space as $(140,17,97)$, that 
can be mapped in: cultural/historical issues (R) 55\%, green issues $(\mathrm{G}) 7 \%$, and urban open space issues (B) 38\%.

Table 1. Colors, Tags and Preferences.

\begin{tabular}{|c|c|c|}
\hline Color & OSM tags & Routing Preferences \\
\hline $\operatorname{Red}-\operatorname{RGB}(255,0,0)$ & $\begin{array}{l}\text { amenity=\{arts_centre, } \\
\text { fountain, university }\} \\
\text { tourism=\{attraction, } \\
\text { artwork, gallery, museum, } \\
\text { viewpoint }\} ; \\
\text { covered=\{arcade, } \\
\text { colonnade }\} ; \\
\text { historic= }\{*-\text { all values }\} .\end{array}$ & $\begin{array}{l}\text { Cultural/historical issues } \\
\text { The path includes the highest } \\
\text { number of nodes, ways, and } \\
\text { relations related to historical, } \\
\text { cultural, and touristic urban } \\
\text { elements. }\end{array}$ \\
\hline Green - RGB $(0,255,0)$ & $\begin{array}{l}\text { natural }=\{*-\text { all values }\} ; \\
\text { landuse }=\{\text { grass }\} ; \\
\text { leisure }=\{\text { garden, park }\} ; \\
\text { tourism }=\{\text { picnic_site }\} .\end{array}$ & $\begin{array}{l}\text { Green issues } \\
\text { The path includes the highest } \\
\text { number of nodes, ways, and } \\
\text { relations related to gardens, parks, } \\
\text { tree-lined streets, green areas. }\end{array}$ \\
\hline Blue - RGB $(0,0,255)$ & $\begin{array}{l}\text { amenity }=\{\text { marketplace }\} \\
\text { highway }=\{\text { pedestrian }\} \\
\text { combined with area }=\{\text { yes }\} \text {. }\end{array}$ & $\begin{array}{l}\text { Urban Open Space issues } \\
\text { The path includes the highest } \\
\text { number of open urban areas (e.g. } \\
\text { squares) and panoramic/scenic } \\
\text { views. }\end{array}$ \\
\hline
\end{tabular}




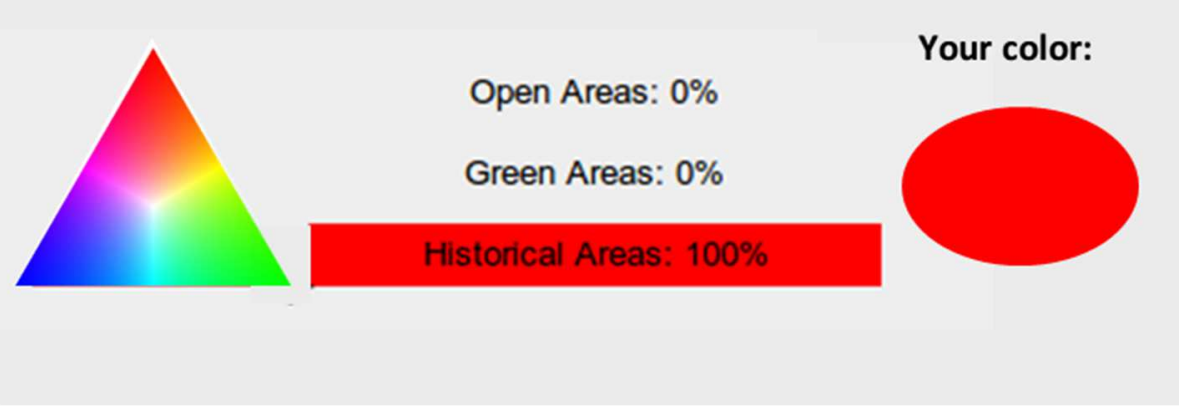

Figure 2 - Mapping between the primary color picked by the user and the routing preferences $(100 \%$ cultural/historical issues).

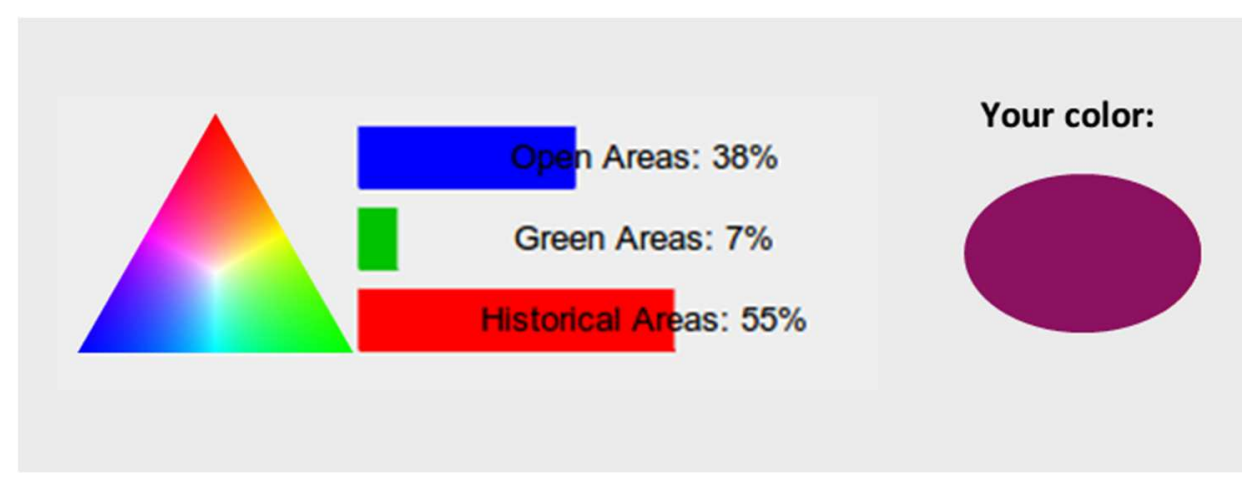

Figure 3 - Mapping between the color picked by the user and the routing preferences.

The mapping of the colors in the three preferences (corresponding to the three primary colors) is calculated as follows:

- $\quad$ culturalFactor $=$ redValue $/($ redValue+greenValue+blueValue $) * 100$;

- $\quad$ greenFactor $=$ greenValue $/($ redValue + greenValue + blueValue $) * 100$;

- $\quad$ openFactor = blueValue $/($ redValue +greenValue +blueValue $) * 100$;

where redValue, greenValue, and blueValue are integer numbers between 0 and 255, in the RGB notation. The three obtained values (culturalFactor, greenFactor, and openFactor) represent the percentages of each user's preference to be mapped in the urban issues. In other words, these three values represent the user's preferences in terms of cultural/historical issues, green issues and open urban space issues as percentages of the whole requested path. In this 
way, the user can pick any color, which is decomposed in the three primary colors (and in the corresponding contributions in terms of urban categories of which the path is constructed out). In other words, the chosen colors are used to compute the route that better fit those colors with the urban environment, as described in the following subsection. Needless to say, the interface allows the user to further adjust the percentage of R, G, and B, so as to obtain a different color (lighter or darker) with respect to the one which was originally picked. If the user does not pick any color, the black one is assumed to be chosen (i.e. absence of colors, in an additive color space), thus resulting into the shortest path. This approach follows the well-known notion of the RGB additive color space, where the black color corresponds to the absence of other colors, hence of light.

We do not provide here any specific guideline for our color-based user interface, since (except for the accessibility issues we have already addressed) main focus of this paper is demonstrating that our color-based intuition can work when applied to the personalization of walking paths.

\subsection{The ColorPath Algorithm}

As anticipated in Table 1, each preference/urban issue is related to some OSM tags. These tags are fundamental in computing the personalized colored path. In order to consider these tags in our algorithm, we have extended the OTP routing engine, which calculates the shorted path using the Dijkstra's algorithm on a graph built by using the OSM data.

The color picked by the user is converted in three floating-point values that are used as weights, ranging from 0.0 to 1.0 , and representing the user-specified routing preferences. Indeed, the sum of the three options is 1 . Such weights are associated to each arch of the graph and multiplied by the cost of the specific arch in term of the number of areas (nodes) that meet the routing preferences in that arch. Hence, the total arch weight is computed as follows: 
archWeight $=($ length $*$ cultureFactor $* \operatorname{cost}(R))+($ length $*$ greenFactor $* \cos t(G))+$

$$
(\text { length } * \text { openFactor } * \operatorname{cost}(B))
$$

where:

- length: is the length of the arch;

- $\operatorname{cost}(X)=1 /((\operatorname{areas}(x)+1))$, where $\operatorname{areas}(\mathrm{x})$ is the number of areas meeting the color preferences, with $X=\{R, G, B\}$ to map the specific routing preference;

- culturalFactor, greenFactor, and openFactor are the three floating values mapping the amount of red, green and blue in the color representing the user's preferences.

This means that the more areas in that arch meet the routing preferences (on the basis of its tags, as reported in Table 1) and the less the arch should weigh (it also depends on the arch length and routing preferences factor). The route that best fits the users' preferences is the one with the lowest weight. Hence, with this configuration, our algorithm is coherent with the $A^{*}$ routing algorithm implemented in OTP, returning the best path which is the less expensive, considering the sum of the combination of the arches' weight between the two points in the map (starting points and destination of the route). The proposed route could be different (longer) from the shortest one between the starting point and the arrival one. It is important to notice that our algorithm automatically cuts off all those paths that are longer than $x+30 \%$ of $x$, where $x$ is the length of the shortest existing path. Such a decision comes from a previous research study [Mirri et al. 2016] with 60 users, where we found that such additional quantity is the maximum cost that users are available to pay, on average, while enjoying pleasant paths. Following this line, Quercia and co-authors found that the more beautiful, quiet and happy routes are just few extra walking minutes than the shortest ones [Quercia et al. 2014]. 
A ColorPath screenshot showing the route corresponding to the purple color (as chosen in Figure 3) is depicted in Figure 4. In this example, the user was in the Bologna Central Station (as starting point of his/her path) and would like to reach the head office of the University of Bologna, placed in Via Zamboni 33 (as destination of the route).

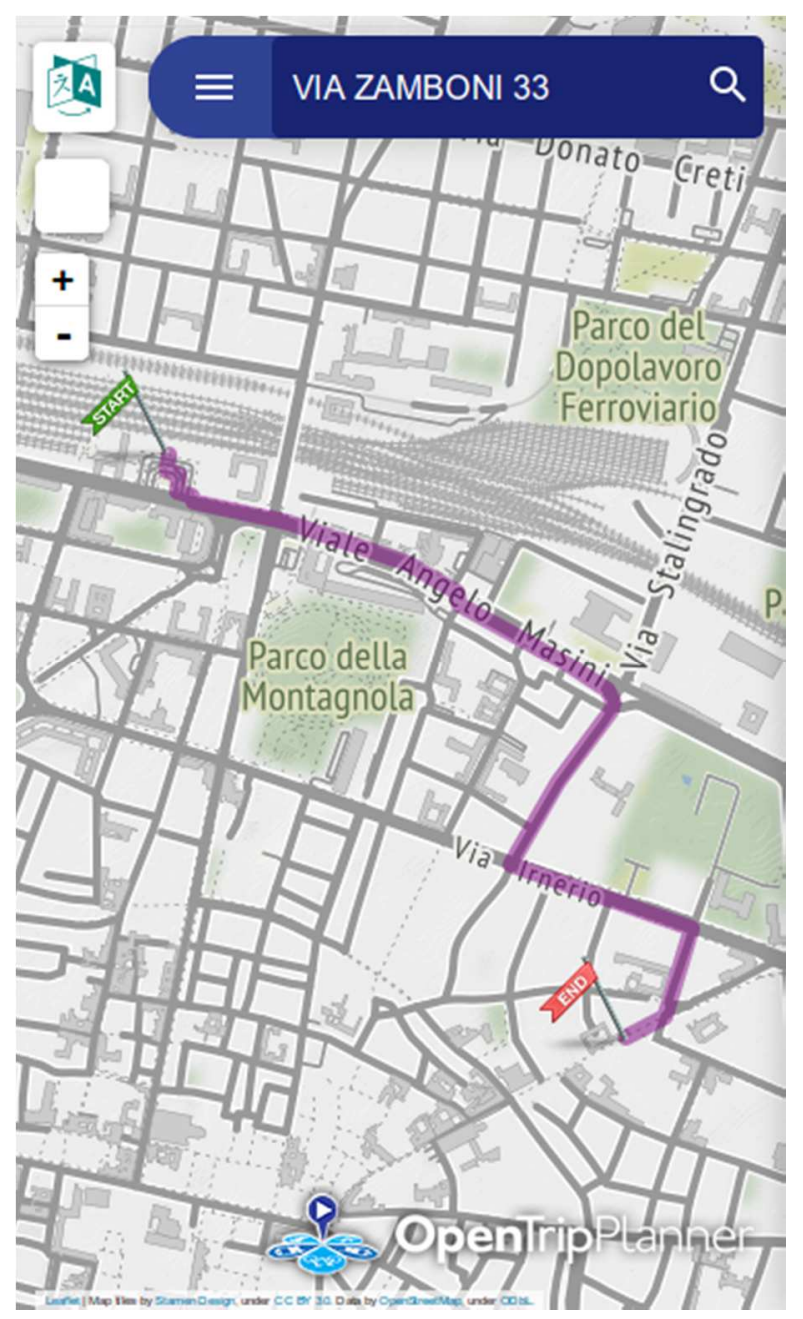

Figure 4 - A screenshot of the ColorPath GUI displaying a colored path in Bologna.

\section{ColorPath in Practice}

The following Section is split over two parts as suggested in [Wohlin, 2000]. In Subsection 4.1 the context of the experiment (also termed planning) is described, while Subsection 4.2 provides quantitative and qualitative results.

\subsection{Planning}


After developing ColorPath, we decided to recruit some users in field trials who denote a target of urban walkers. For this reason, we asked 10 people ( 5 males and 5 females, with age ranging from 22 to 56 years), who daily use to walk across Bologna while reaching their workplace, to experience our mobile application. These users were engaged among students, colleagues, relatives, and acquaintances. The size of this sample of users is motivated by the need to obtain rapidly some preliminary, yet relevant, results. We plan to collect more data with more participants in future experiments.

Our users exploited a web-app version of ColorPath on their own mobile devices; seven of them were equipped with Android operating systems, while the other ones were iPhone devices. We conducted separated sessions of the test, which took one hour each and then we asked users to fill a questionnaire.

We asked them to walk on an urban path starting from the Central Station and arriving in Via Zamboni 33 (head office of the University of Bologna). This resulted as the shortest route (characterized by the black color), since they did not yet choose any color. We accompanied them in this shortest path and we talked with them, inviting to say whatever came into their mind as they walked along the path, describing what they were seeing and how they were feeling (taking inspiration from the "Think Aloud Protocol" [Lewis, 1982]).

Once reached the destination of the shortest path, we asked users to invert the destination and the starting point (from Via Zamboni 33 to the Central Station), so as to come back to the original point, and then we requested users to choose a color, according to their mood and/or their preferences. Again, we accompanied the users in these different paths computed by ColorPath, tailored according to the combination of primary colors. The color the user has chosen expresses a mixture of historical buildings and places (red), parks and gardens (green), and pleasurable landscapes (blue). On this way back, we invited users to express their feeling 
according to the urban elements that were around. Figure 5 shows a map of Bologna with the shortest path (black colored, Figure 5a) and the colored path chosen by one of our user (Figure 5b). Figure 6 shows a picture of a user taken during the colored path, while she was experiencing ColorPath.

After each field trial, we involved the users in filling a survey related to ColorPath. The survey was composed of 10 items, related to the goals of the system and connected to the colored path they experienced. We use the Likert scale [Bertram, 2016] approach in ranking the first seven questions based on a 5 values symmetric agree-disagree scale, in order of strength. In particular, the adopted scale was as follows: strongly agree, agree, neutral, disagree, strongly disagree. Questions of this survey are reported in Table 2.

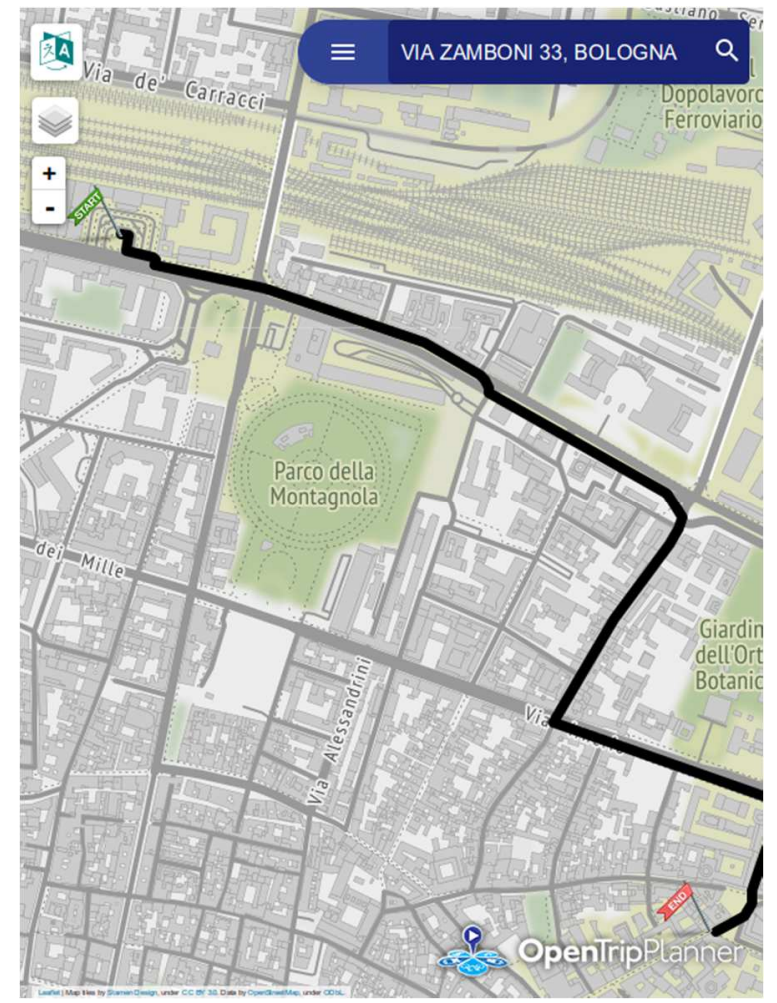

(a) The shortest (black colored) path

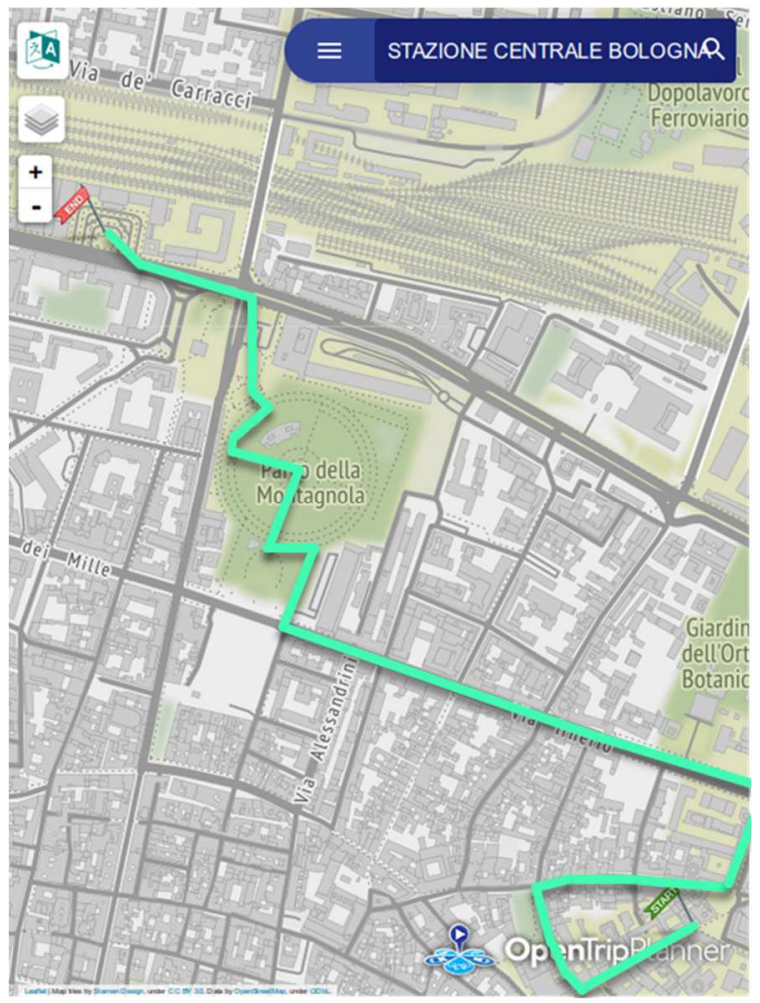

(b) The colored (green-based) and personalized path

Figure 5-Maps of Bologna with the shortest and the colored paths between the starting point and the destination 
The last three questions aim to let the user evaluate and quantify with an integer number (ranging from 0 to 100) the amount of the following items along the path:

- historical buildings and places (culturalFactor, corresponding to the quantity of red);

- $\quad$ parks and gardens (greenFactor, corresponding to the quantity of green);

- pleasurable landscapes (openFactor, corresponding to the quantity of blue).

We exploited such an estimation with the aim of comparing the chosen color with the urban elements actually characterized the route proposed by ColorPath. We decided to propose 0-100 scale because users who are not experts in color theory could find the 0-255 range as confusing. Needless to say, this decision is paid in terms of a loss of accuracy that does not result critical to the aim of this study.

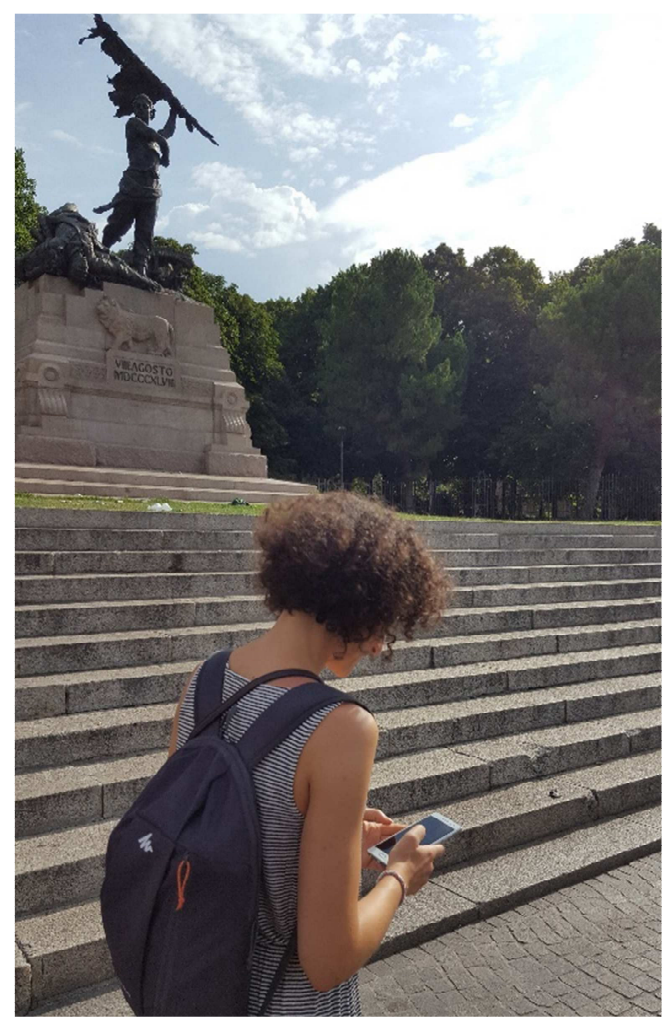

Figure 6 - A user while walking with ColorPath in Bologna 
Table 2. Survey questions (and answer models).

\begin{tabular}{|c|c|c|}
\hline Nr. & Question & Answer Model \\
\hline 1 & $\begin{array}{l}\text { I've preferred the proposed colored path instead of the } \\
\text { shortest (black) one. }\end{array}$ & $\begin{array}{ll} & \text { strongly agree, } \\
\text { - } & \text { agree, } \\
\text { - } & \text { neutral, } \\
\text { - } & \text { disagree, } \\
\text { - } & \text { strongly disagree }\end{array}$ \\
\hline 2 & $\begin{array}{l}\text { The proposed colored path is not much longer than the } \\
\text { shortest (black) one. }\end{array}$ & $\begin{array}{ll}\text { - } & \text { strongly agree, } \\
\text { - } & \text { agree, } \\
\text { - } & \text { neutral, } \\
\text { - } & \text { disagree, } \\
\text { - } & \text { strongly disagree }\end{array}$ \\
\hline 3 & $\begin{array}{l}\text { I would like to walk again along the proposed colored } \\
\text { path, instead of the shortest black path. }\end{array}$ & $\begin{array}{ll}\text { - } & \text { strongly agree, } \\
\text { - } & \text { agree, } \\
\text { - } & \text { neutral, } \\
\text { - } & \text { disagree, } \\
\text { - } & \text { strongly disagree }\end{array}$ \\
\hline 4 & $\begin{array}{l}\text { I agree with the association of cultural factors } \\
\text { (historical buildings and places) with the Red color. }\end{array}$ & $\begin{array}{ll}\text { - } & \text { strongly agree, } \\
\text { - } & \text { agree, } \\
\text { - } & \text { neutral, } \\
\text { - } & \text { disagree, } \\
\text { - } & \text { strongly disagree } \\
\end{array}$ \\
\hline 5 & $\begin{array}{l}\text { I agree with the association of green factors (parks and } \\
\text { gardens) with the Green color. }\end{array}$ & $\begin{array}{ll}\text { - } & \text { strongly agree, } \\
\text { - } & \text { agree, } \\
\text { - } & \text { neutral, } \\
\text { - } & \text { disagree, } \\
\text { - } & \text { strongly disagree }\end{array}$ \\
\hline 6 & $\begin{array}{l}\text { I agree with the association of open factors (pleasurable } \\
\text { landscapes) with the Blue color. }\end{array}$ & $\begin{array}{ll}- & \text { strongly agree, } \\
\text { - } & \text { agree, } \\
\text { - } & \text { neutral, } \\
\text { - } & \text { disagree, } \\
\text { - } & \text { strongly disagree } \\
\end{array}$ \\
\hline 7 & $\begin{array}{l}\text { I've chosen the color according to my preferences } \\
\text { without taking into account associated urban elements. }\end{array}$ & $\begin{array}{ll}\text { - } & \text { strongly agree, } \\
\text { - } & \text { agree, } \\
\text { - } & \text { neutral, } \\
\text { - } & \text { disagree, } \\
\text { - } & \text { strongly disagree }\end{array}$ \\
\hline 8 & $\begin{array}{l}\text { From } 0 \text { to } 100, \text { may you quantify the presence of } \\
\text { historical buildings in the proposed colored path? }\end{array}$ & An integer value, ranging from 0 to 100 \\
\hline 9 & $\begin{array}{l}\text { From } 0 \text { to } 100, \text { may you quantify the presence of parks } \\
\text { and gardens in the proposed colored path? }\end{array}$ & An integer value, ranging from 0 to 100 \\
\hline 10 & $\begin{array}{l}\text { From } 0 \text { to } 100, \text { may you quantify the presence of } \\
\text { pleasurable landscapes in the proposed colored path? }\end{array}$ & An integer value, ranging from 0 to 100 \\
\hline
\end{tabular}


Moreover, we gave participants the possibility to provide personal comments during the walks, while we have taken notes. Obtained data were analyzed from both a quantitative viewpoint and from a qualitative perspective, obtaining interesting results.

\subsection{Results}

In this Subsection, we provide a quantitative analysis and a qualitative analysis of the comparisons among the shortest path, the expected colored path (according to users' selections), and the effectively provided one (computed by ColorPath on the basis of the algorithm described in Subsection 3.2). It is important to mention that, in the following discussion, all participant names are pseudonyms.

On a quantitative perspective, a first element of interest is the fact that all the users appreciated the proposed colored path (Question 1), claiming they would walk again along it (Question 3), and just one of them payed attention to the extra-length of the second path, compared with the shortest one (Question 2), as reported in Figure 7. Indeed, this latter issue was not surprising and it can be easily brought back to the results coming from [Quercia et al. 2014] and [Mirri et al. 2016]. Matteo, during the second route (the colored one), said:

"This route is too long; the view was nice, sure, but it took so much time, it is a waste of time, I would not walk again on it."

While Sara claimed:

"I use to walk every day from the train station to the University campus, and today for the first time I have discovered little streets of Bologna I've never crossed."

Both these comments come from the think aloud data we have collected during the experiments. 


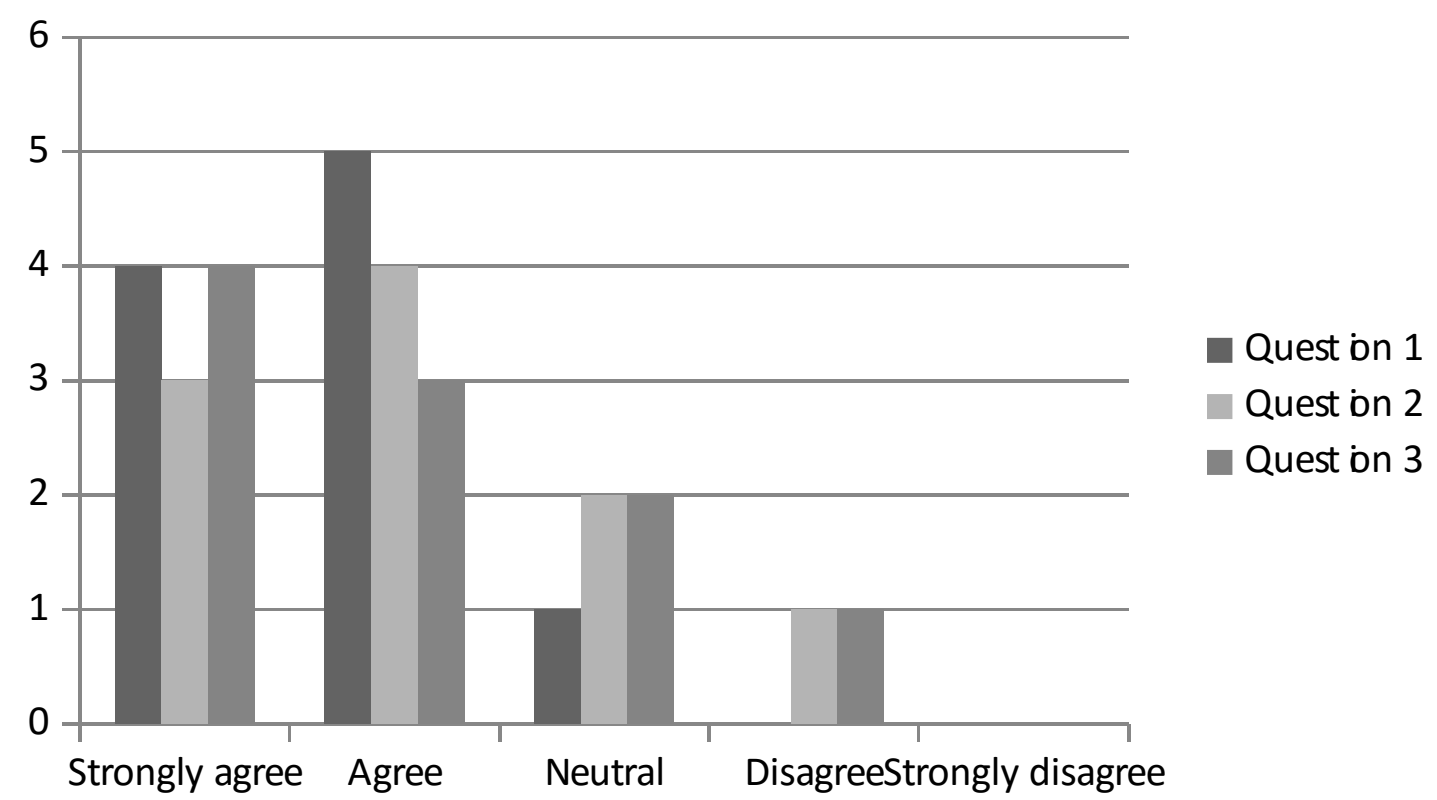

Figure 7 - Users' appreciation about the colored path (Question 1), users' perception about similarity in length of the proposed colored path compared with the shortest one (Question 2), users' intention of walking again along the proposed colored path (Question 3)

Table 3 reports a comparison between the shortest path and the colored ones in terms of length (expressed in kilometers) and in terms of walking time. The shortest colored path was 1.7 kilometers (just 100 meters longer than the shortest - black colored - path), while the longest one was 2.2 kilometers.

Then, we asked users if they agree or not with the meanings we have associated to the three primary colors and with the relationships with the urban elements. Just one user is Neutral regarding the meaning associated to the color Blue, related to the open space urban elements, while all the other ones agreed or strongly agreed with our use of color in the configuration and preferences system of ColorPath.

Figure 8 shows the users' answers related to the use of the color Red, Green and Blue. In particular, Angelo affirmed:

\section{"Bologna is the red city. No doubt about that!"}

Francesca maintained: 
"I like the idea of having a personalization that drives me to see and enjoy the sky while walking in the city center of Bologna. That is not so easy: streets in the old town are narrow, buildings are so closed each other."

Again, the above comments come from the think aloud data we have collected during the experiments.

Table 3 - Comparison between the shortest path and the colored proposed ones in terms of kilometers and of walking time

\begin{tabular}{|l|r|r|r|r|}
\hline \multirow{2}{*}{ Users } & \multicolumn{2}{|c|}{ Shortest path } & \multicolumn{2}{c|}{ Colored path } \\
\cline { 2 - 5 } & Time (minutes) & Distance (km) & Time (minutes) & Distance (km) \\
\hline $\mathbf{1}$ & $21 \mathrm{~m}$ & $1,6 \mathrm{~km}$ & $22 \mathrm{~m}$ & $1,7 \mathrm{~km}$ \\
\hline $\mathbf{2}$ & $20 \mathrm{~m}$ & $1,6 \mathrm{~km}$ & $28 \mathrm{~m}$ & $2,2 \mathrm{~km}$ \\
\hline $\mathbf{3}$ & $23 \mathrm{~m}$ & $1,6 \mathrm{~km}$ & $25 \mathrm{~m}$ & $1,7 \mathrm{~km}$ \\
\hline $\mathbf{4}$ & $24 \mathrm{~m}$ & $1,6 \mathrm{~km}$ & $26 \mathrm{~m}$ & $1,9 \mathrm{~km}$ \\
\hline $\mathbf{5}$ & $20 \mathrm{~m}$ & $1,6 \mathrm{~km}$ & $22 \mathrm{~m}$ & $1,8 \mathrm{~km}$ \\
\hline $\mathbf{6}$ & $21 \mathrm{~m}$ & $1,6 \mathrm{~km}$ & $22 \mathrm{~m}$ & $1,7 \mathrm{~km}$ \\
\hline $\mathbf{7}$ & $25 \mathrm{~m}$ & $1,6 \mathrm{~km}$ & $29 \mathrm{~m}$ & $1,9 \mathrm{~km}$ \\
\hline $\mathbf{8}$ & $24 \mathrm{~m}$ & $1,6 \mathrm{~km}$ & $30 \mathrm{~m}$ & $2 \mathrm{~km}$ \\
\hline $\mathbf{9}$ & $26 \mathrm{~m}$ & $1,6 \mathrm{~km}$ & $33 \mathrm{~m}$ & $2,2 \mathrm{~km}$ \\
\hline $\mathbf{1 0}$ & $22 \mathrm{~m}$ & $1,6 \mathrm{~km}$ & $24 \mathrm{~m}$ & $1,8 \mathrm{~km}$ \\
\hline & & & & \\
\hline
\end{tabular}

To assess the significance of the experimental results from a statistical view point, we carried out an additional statistical analysis. In particular, for the first three items in the questionnaire we defined a null hypothesis and calculated the corresponding p-value using the standard twotailed formula for the one sample t-test. As each item in the questionnaire can be responded 
with a value in the interval $[-2,2]$, we assumed 0 as the expected average value (accordingly with the related null hypothesis) and considered a confidence level as great as the $95 \%$. Hence, the level of significant was set to 0.05 . From an analysis of Table 4, it is easy to verify that each of these $\mathrm{p}$-values calculated were smaller than the 0.05 thus providing a statistical significance to our experiments and allowing us to reject each null hypothesis.

Finally, we have compared the proposed paths with the users' expectation, according to the chosen color, and let the users quantify from 0 to 100 the quantity of historical buildings and places (red), parks and gardens (green), and pleasurable landscapes (blue) they met during the path. Then, we converted those results into the RGB notation, so as to obtain a color that represents the perceived color corresponding to the walked path. Thus, we have computed the Euclidean distance between this perceived color and the chosen one on ColorPath. Such a Euclidean distance has been computed according to the Delta-E algorithm [Sharma and Bala, 2002], after converting them into the CIE*Lab color space [Connolly and Fleiss, 1997].

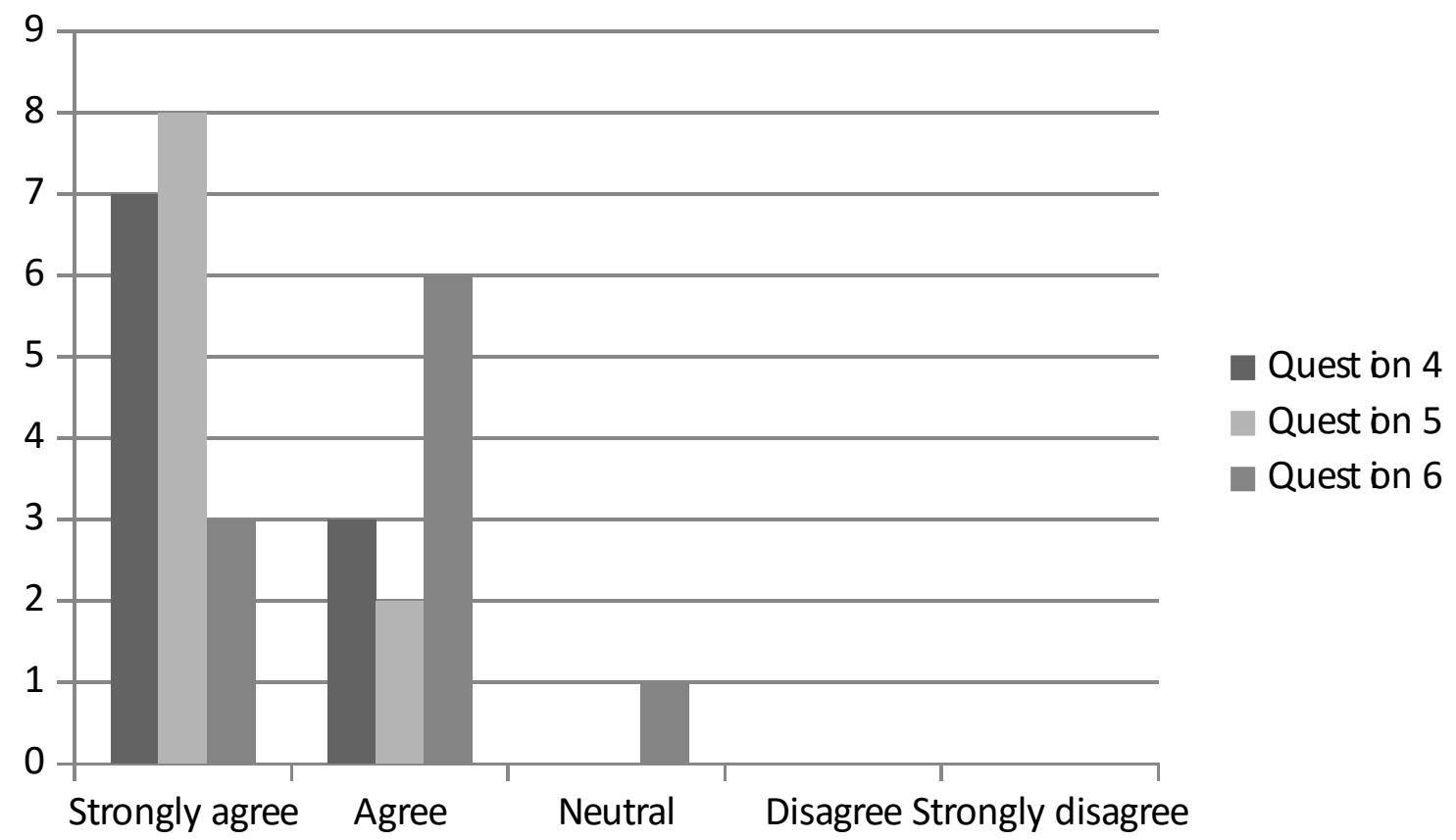

Figure 8 - Users' agreement about the meaning associated to the colors Red (Question 4), Green (Question 5) and Blue (Question 6) and related urban elements 
Table 4 - One sample t-test analysis and relative measurement for the first three questions.

\begin{tabular}{|c|c|c|c|c|c|c|}
\hline Question & Null hypothesis & $\mathrm{p}$ value & t statistic & Mean & St. Dev. & St. Error \\
\hline 1 & $\begin{array}{l}\text { There are no difference } \\
\text { between the shortest } \\
\text { paths and the colored one } \\
\text { (in term of pleasantness). }\end{array}$ & 0.0002 & 6.0908 & 1.30 & 0.67 & 0.21 \\
\hline 2 & $\begin{array}{l}\text { There are difference } \\
\text { between the shortest } \\
\text { paths and the colored one } \\
\text { (in term of perceived } \\
\text { length). }\end{array}$ & 0.0187 & 2.8620 & 0.90 & 0.99 & 0.31 \\
\hline 3 & $\begin{array}{l}\text { There are no advantages } \\
\text { in walking the colored } \\
\text { path. }\end{array}$ & 0.0150 & 3.0000 & 1.00 & 1.05 & 0.33 \\
\hline
\end{tabular}

Table 5 reported such comparisons for all the 10 involved users. In particular, for each user we have reported:

- the chosen color picked by the user on the ColorPath interface (as shown in Figure 2 and Figure 3) during the test and decomposed into the three main colors, Red, Green, and Blue.

- The perceived color, computed as the combination of the quantity of historical buildings and places (Red), parks and gardens (Green), and pleasurable landscapes (Blue) and then converted into RGB notation, as described above. Hence, the users did not express the final perceived colors by means of an interface similar to the prototyped one they have interacted with during the tests (as shown in Figure 2 and Figure 3), but they declared the quantities corresponding to the categories of urban elements. Table 5 reports the corresponding quantities of Red, Green, and Blue, together with the color resulting from their combination as the perceived color.

- The distance between the chosen and the perceived colors.

In general, we can observe that the perceived colors are darker than the chosen ones and they show a prominent presence of the red component compared with the green and the blues ones. This is mainly because Bologna has a large and well-preserved historical center, 
characterized by medieval towers, antique buildings, and churches. Moreover, this also confirms the nickname "the red one" for Bologna: all the paths the users chose were placed in the city center and that area of Bologna is featured by buildings made of red bricks and roofs, a well-known and typical characteristic of the city where these experiments were conducted. In simpler words, quite surprisingly, the column of perceived colors in Table 5 reports in general darker nuances with the respect to the column of the chosen colors, this is simply due to the fact that the Red color is predominant in the city of Bologna and, hence, strongly perceived by the people who carried out the experiments.

The minimum distance is the one obtained by User 10 (25), while the maximum is the one stated by User 2 (63), as reported in Table 5.

Table 5 - Differences between chosen colors and perceived colors

\begin{tabular}{|c|c|c|c|c|c|c|c|c|c|}
\hline \multirow{2}{*}{ Users } & \multicolumn{4}{|c|}{ Chosen color } & \multicolumn{4}{|c|}{ Perceived color } & \multirow{2}{*}{ Delta-E distance } \\
\hline & Red & Green & Blue & Color & Red & Green & Blue & Color & \\
\hline 1 & 125 & 62 & 214 & & 128 & 64 & 102 & & 63 (max value) \\
\hline 2 & 242 & 244 & 80 & & 230 & 153 & 77 & & 53 \\
\hline 3 & 67 & 250 & 179 & & 77 & 153 & 26 & & 48 \\
\hline 4 & 255 & 192 & 203 & & 230 & 115 & 102 & & 44 \\
\hline 5 & 255 & 165 & 0 & & 204 & 77 & 13 & & 42 \\
\hline 6 & 252 & 7 & 244 & & 217 & 26 & 153 & & 42 \\
\hline 7 & 255 & 255 & 0 & & 230 & 179 & 26 & & 40 \\
\hline 8 & 0 & 255 & 255 & & 51 & 166 & 179 & & 35 \\
\hline 9 & 237 & 149 & 61 & & 217 & 77 & 26 & & 31 \\
\hline 10 & 252 & 162 & 73 & & 230 & 102 & 26 & & 25 (min value) \\
\hline
\end{tabular}


In order to show the maximum and the minimum distances among the chosen colors and the perceived ones, we have reported colors related to User 2, User 4 and User 10 into the sRGB color triangle [Anderson et al. 1996], as depicted in Figure 9. In particular, the minimum distance value reported in the Figure is mainly related to the Red component of the colors (and corresponding to chosen and perceived colors by User 10, in Table 5). The maximum value (related to User 2, in Table 5) is due to a high difference between the Blue component of the chosen and of the perceived colors: in fact, in the proposed path there were few pleasurable landscapes compared with the user's requests. This can be motivated by the area of the starting point and the destination, which is a historical part of the city with ancient buildings and with little and narrow streets and with very few panoramic and scenic views.

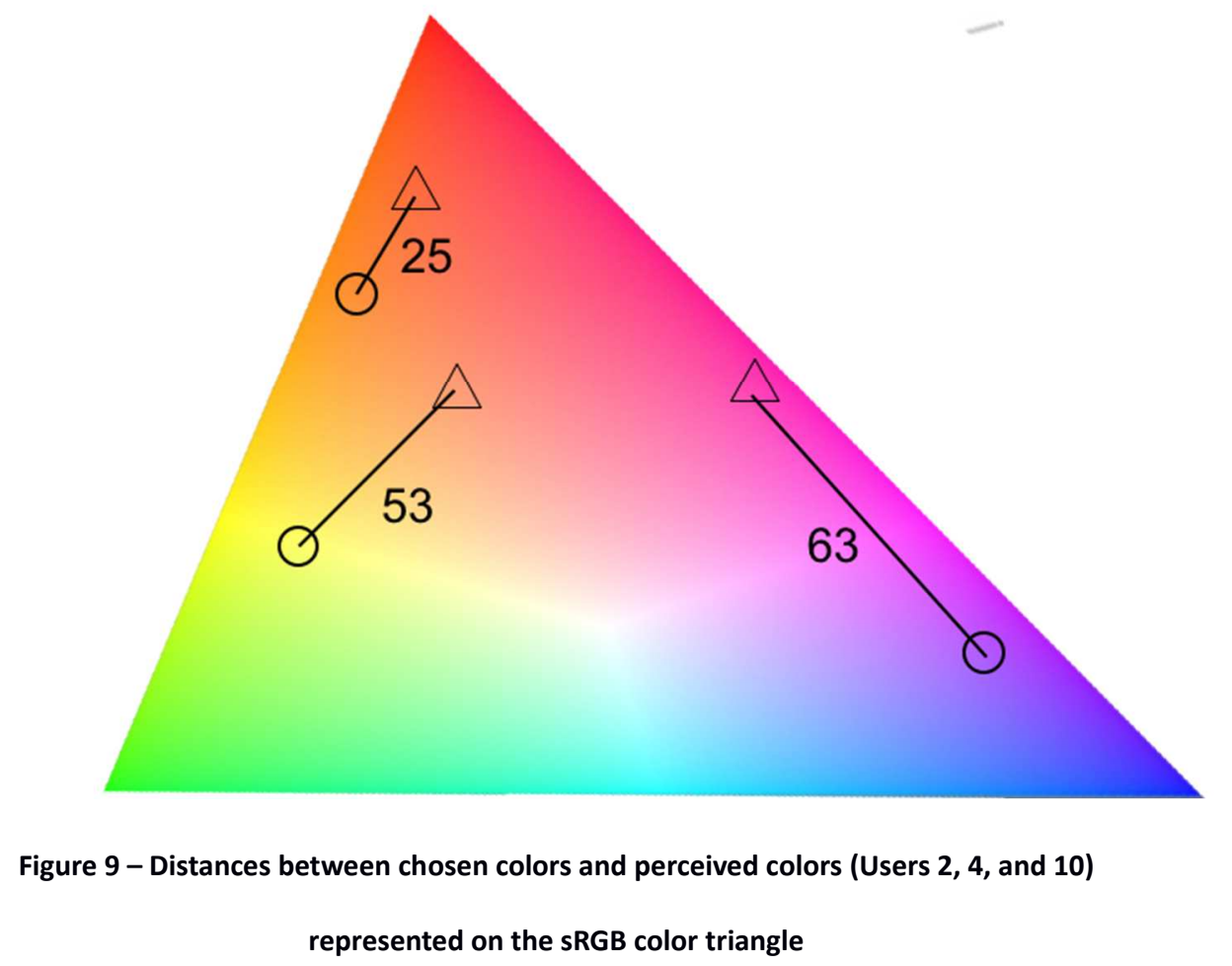

The third distance value shown in Figure 9 (53, corresponding to User 4 in Table 5) is the second highest value and it is mainly motivated by the distance between the Green component of the chosen and the perceived colors: again, this can derive from the presence of 
just very few green areas in that area of Bologna. Only two users disagreed about the similarity of the chosen color and the perceived one. Pietro claimed:

"I thought I would have more blue and green in my route, but there was too much red. I have not realized before that Bologna is so red. It is truly red."

While Elisa said:

"The path I got was surrounded by historical and ancient buildings. I was dipped in the history of the city. May I try another color? And another path? I would like to walk within more green and blue."

Both these comments from Pietro and Elisa have been collected during the think aloud tests.

\subsection{Discussion}

Drawing on Lynch and his pioneering work, we can reflect on the fact that each citizen perceives the urban environment s/he lives in a different, personal, (and somehow partial) way. Her/his imagery of a city is in fact influenced by buildings and architectural elements, yet other contextual elements can strongly concur in defining it, as argued in [Lynch, 1960], [Boeschenstein, 1986]. Nonetheless, composing such an image in people's minds is a complex process that may also depend on their moods, feelings and sensations, which in turn can change, even time by time over the same day. For this reason, emotional factors are recognized to become a kind of filter through which people look at the city where they live, so that the initial neutral perceptual input we all see as similar can turn into a corresponding image of a given urban environment that may vary significantly depending on the "perspective" of any given observer [Lynch, 1960], [Terwogt and Hoeksma, 1995].

Building on this, our empirical study has tried to consider that role that primary colors play on the perception of the imagery we create in our mind of a given city, in simpler words: the personal vision we have of it when colors come on stage. In this context, with the experiment 
we have conducted people have explored urban "colored" paths, which are different from the ones they are typically used to walk over. The idea of proposing a path based on the choice of a specific color had the intention to liberate the mind of walkers from the rigid attitude to choose the shortest one, with the hope to let them experience new aspects of the urban environment they live, and often do not know very well.

Interestingly, one of the most prominent result we have obtained is a confirmation that color is one of the most immediate methods for conveying meaning and sense towards people, while exploiting new media-based technologies, as already mentioned in [Eiseman 2006]. Second, the quantitative and qualitative analysis we have conducted, after our experiments, shows that using colors significantly influence the way people choose their routes, letting them reconstruct a new and personal vision of the places of their lives [Valdez and Mehrabian, 1994]. To this aim, consider for example comments such as: "I never realized before that Bologna is that red. It is truly red" (Pietro) or "I'm discovering unexpected green corners in downtown Bologna" (Valentina).

Interesting is also the fact that walkers who broke their habits to follow ColorPath (instead of their usual daily route) have shown to feel safe during those new explorations, since ColorPath had in some sense provided them with an emotional support to explore new and different city areas; in some sense mitigating the feeling of discomfort that one can experience when $\mathrm{s} / \mathrm{he}$ is on her/his way, along a partially unknown path. It seems almost that the meaning of "sense of emotional security" described by Lynch have resurfaced here with our color based routing application. We guess that ColorPath in fact mitigates the sense of disorientation as it proposes to reach the required well-known final destination through routes that are perceived as more pleasant, on average. As a confirmation, consider the fact that, on the final evaluation, 9 over 10 users had preferred the colored paths instead of the shortest one. Further confirmations emerge from comments such as: "I have been working in this area of Bologna since 1996 and 
this is the first time I enjoy walking across a different path" (Angelo) and “... today for the first time I have discovered little streets of Bologna I've never crossed" (Sara).

A final consideration on the results we have obtained pertains the fact that our experiments were conducted over spaces (the city of Bologna) where the presence of the red color is massive, if compared with green and blue of parks, gardens and open landscapes. This was also clearly perceived, "ex-post", by our walkers who have generally judged the red color as prevalent during their walks, against green and blue, yet with an intensity they did not realize before the experiments. This simply means that some cities may tend unfortunately to be monochromatic, as discussed in [Boeschenstein, 1986]. Our study has revealed how much people would enjoy more differently colored urban environments that would better meet their moods and feelings.

\section{Conclusion}

This paper described the design process, the implementation and field trials from which we went through with the aim of equipping urban walkers with a GIS-based mobile application to compute personalized paths across the city, according to a chosen color. That color is de-composed into three primary colors (red, green, and blue), representing the walkers' preferences in terms of urban elements mixed together met along that path. In particular, historical buildings and places are associated to the color red, parks and gardens are associated to the color green, and, finally, pleasurable landscapes are associated to blue color. Ten users have evaluated such an application, named ColorPath. They have enjoyed different paths with the same starting point and destination in the city of Bologna, and they have compared the shortest path with the one proposed by ColorPath. Results confirm the feasibility of our approach. In particular, the involved users showed no worries about facing a longer path when this meets their preferences, confirming previous and related studies. Only one user declared 
he would prefer the shortest path and he would not be interested in experiencing new paths and new slices of the city, without changing his routing, even if he evaluated as pleasant the route proposed by ColorPath. Another interesting result emerged from the field trials we conducted: the distance between the perceived and the chosen colors (i.e. the expected path and the route proposed by ColorPath) is limited. In general, the perceived colors have a higher Red value if compared with the chosen colors. The main reason is related to the layout and the topology of Bologna, where our trials took place. Concluding, the results we got suggest further investigations, involving more users in different cities. In particular, an interesting future works is conducting field trials in rural contexts and in different urban environments, with different landscapes and development along the history of the city. This would let us analyze users' feedback after having walked paths in more green areas, with more panoramic and scenic views. Last, but not least, our results confirm that, yes, Bologna is the "red one".

\section{Acknowledgement}

We thank all the participants involved in this study.

\section{References}

Anderson, M., Motta, R., Chandrasekar, S., \& Stokes, M. (1996, January). Proposal for a standard default color space for the internet—srgb. In Color and imaging conference (Vol. 1996, No. 1, pp. 238-245). Society for Imaging Science and Technology.

Backhaus, W. G., Kliegl, R., \& Werner, J. S. (Eds.). (1998). Color vision: Perspectives from different disciplines. Walter de Gruyter.

Bertram, D. (2007). Likert scales. Retrieved July, 20, 2016. URL: http://poincare.matf.bg.ac.rs/ kristina/topic-dane-likert.pdf 
Boeschenstein, W. (1986). Expressive urban color. Journal of Architectural and Planning Research, 275-285.

Bonnardel, N., Piolat, A., \& Le Bigot, L. (2011). The impact of colour on Website appeal and users' cognitive processes. Displays, 32(2), 69-80.

Brock, A. M., Truillet, P., Oriola, B., Picard, D., \& Jouffrais, C. (2015). Interactivity improves usability of geographic maps for visually impaired people. Human-Computer Interaction, 30(2), 156-194.

Connolly, C., \& Fleiss, T. (1997). A study of efficiency and accuracy in the transformation from RGB to CIELAB color space. IEEE Transactions on Image Processing, 6(7), 1046-1048.

Csurka, G., Skaff, S., Marchesotti, L., \& Saunders, C. (2010, December). Learning moods and emotions from color combinations. In Proceedings of the Seventh Indian Conference on Computer Vision, Graphics and Image Processing (pp. 298-305). ACM.

Cyr, D., Head, M., \& Larios, H. (2010). Colour appeal in website design within and across cultures: A multi-method evaluation. International journal of human-computer studies, $68(1), 1-21$.

Ebeling, K. (2009). Holi, an Indian Festival, and its Reflection in English Media. Linguistischen Kolloquiums in Mannheim 2006, 24, 107.

Eisemann, L. (2000). Pantone's Guide to Communicating with Color. How Books.

Eiseman, L. (2006). Color-Messages \& Meanings: A PANTONE Color Resource. North Light Books.

Gaunet, F., \& Briffault, X. (2005). Exploring the functional specifications of a localized wayfinding verbal aid for blind pedestrians: simple and structured urban areas. HumanComputer Interaction, 20(3), 267-314. 
Guo, H., \& Cai, Y. (2012). Colors Characterize Cities. In Civil Engineering and Urban Planning 2012 (pp. 168-172). ASCE.

Kaya, N., \& Epps, H. H. (2004). Relationship between color and emotion: A study of college students. College student journal, 38(3), 396.

Levy, B. I. (1984). Research into the psychological meaning of color. American Journal of Art Therapy.

Lewis, C. (1982). Using the" thinking-aloud" method in cognitive interface design. IBM TJ Watson Research Center.

Ling, J., \& Van Schaik, P. (2002). The effect of text and background colour on visual search of Web pages. Displays, 23(5), 223-230.

Lynch K. (1960). The image of the city. Volume 11. The MIT Press.

McCarthy, M. (1959). The stones of Florence. Harcourt, Brace.

Mirri, S., Prandi, C., Salomoni, P., Callegati, F., \& Campi, A. (2014a, September). On combining crowdsourcing, sensing and open data for an accessible smart city. In 2014 Eighth International Conference on Next Generation Mobile Apps, Services and Technologies (pp. 294-299). IEEE.

Mirri, S., Prandi, C., \& Salomoni, P. (2014b, July). A context-aware system for personalized and accessible pedestrian paths. In High Performance Computing \& Simulation (HPCS), 2014 International Conference on (pp. 833-840). IEEE.

Mirri, S., Prandi, C., \& Salomoni, P. (2016, January). Personalizing Pedestrian Accessible way-finding with mPASS. In 2016 13th IEEE Annual Consumer Communications \& Networking Conference (CCNC) (pp. 1119-1124). IEEE.

Muller, M., Millen, D. R., \& Strohecker, C. (2001, March). What makes a representative user representative? A participatory poster. In $\mathrm{CHI} 01$ extended abstracts on Human factors in computing systems (pp. 101-102). ACM. 
Murray, D. C., \& Deabler, H. L. (1957). Colors and mood-tones. Journal of applied psychology, 41(5), 279.

Noyes, M. T. (2009). Bologna Reflections. Lulu. com. ISBN: 9780578016832.

Oviatt, S. (1997). Multimodal interactive maps: Designing for human performance. Human-computer interaction, 12(1), 93-129.

Palazzi, C. E., Teodori, L., \& Roccetti, M. (2010, July). Path 2.0: A participatory system for the generation of accessible routes. In Multimedia and Expo (ICME), 2010 IEEE International Conference on (pp. 1707-1711). IEEE.

Prandi, C., Ferretti, S., Mirri, S., \& Salomoni, P. (2015, March). Trustworthiness in crowd-sensed and sourced georeferenced data. In Pervasive Computing and Communication Workshops (PerCom Workshops), 2015 IEEE International Conference on (pp. 402-407). IEEE.

Quercia, D., Schifanella, R., \& Aiello, L. M. (2014, September). The shortest path to happiness: Recommending beautiful, quiet, and happy routes in the city. In Proceedings of the 25th ACM conference on Hypertext and social media (pp. 116-125). ACM.

Roccetti, M., Marfia, G., \& Palazzi, C. E. (2011). Entertainment beyond divertissment: using computer games for city road accessibility. Computers in Entertainment (CIE), 9(2), 10.

Rosner, D. K., Saegusa, H., Friedland, J., \& Chambliss, A. (2015, April). Walking by Drawing. In Proceedings of the 33rd Annual ACM Conference on Human Factors in Computing Systems (pp. 397-406). ACM.

Sharma, G., \& Bala, R. (Eds.). (2002). Digital color imaging handbook. CRC press. Terwogt, M. M., \& Hoeksma, J. B. (1995). Colors and emotions: Preferences and combinations. The Journal of general psychology, 122(1), 5-17.

Valdez, P., \& Mehrabian, A. (1994). Effects of color on emotions. Journal of experimental psychology: General, 123(4), 394. 
von Helmholtz, H. (1925). Helmholtz's treatise on physiological optics (Vol. 3). Optical Society of America.

Waldman, G. (2002). Introduction to light: The physics of light, vision, and color. Courier Corporation.

Wood, D., Kaiser, W. L., \& Abramms, B. (2006). Seeing through maps: Many ways to see the world. New Internationalist.

Wohlin, C., Runeson, P., Höst, M., Ohlsson, M. C., Regnell, B., \& Wesslén, A. (2012). Experimentation in software engineering. Springer Science \& Business Media.

\section{Authors' Biography}

Silvia Mirri is assistant professor at the Department of Computer Science and Engineering at the University of Bologna (Italy). She was also a Visiting Researcher at the University of Toronto (Ontario, Canada). Her research interests focus on multimedia and Web applications and technologies, Human Computer Interaction, and accessibility.

Catia Prandi is a research fellow at the Interdepartmental Centre for Industrial ICT Research at the University of Bologna (Italy). She was Visiting Researcher at the MITI at the University of Madeira (Portugal) and at the KMI at the UK Open University. Her research interests focus on Human Computer Interaction.

Marco Roccetti is full professor of Computer Science at the University of Bologna (Italy). He was also a Visiting Scholar at the University of California Los Angeles and a Visiting Scientist at the International Computer Science Institute in Berkeley. His research interests focus on digital multimedia applications and allied technologies.

Paola Salomoni is associate professor at the Department of Computer Science and Engineering at the University of Bologna (Italy). She is currently serving as Vice Rector to Digital Technologies at the University of Bologna. Her research interests focus on multimedia and Web applications and technologies, Human Computer Interaction, and accessibility. 